\title{
In Silico Assessment of Drug-Like Properties of Phytocannabinoids in Cannabis Sativa
}

\author{
Shakinaz Desa ${ }^{1 *}$, Asiah Osman ${ }^{2}$, and Richard Hyslop ${ }^{3}$ \\ ${ }^{1}$ Department of Biology, Universiti Pendidikan Sultan Idris, Malaysia, \\ ${ }^{2}$ Natural Product Division, Forest Research Institute Malaysia, \\ ${ }^{3}$ Department of Chemistry and Biochemistry, University of Northern Colorado, USA \\ *Corresponding author: shakinaz@fsmt.upsi.edu.my
}

\begin{abstract}
This study investigated drug-like properties of phytocannabinoids in Cannabis sativa using an in silico study. We report sixteen phytocannabinoids: cannabidiol (CBD), cannabidiolic acid (CBDA), cannabinol (CBN), cannabichromene (CBC), cannabigerol (CBG), cannabicyclol (CBL), cannabivarin (CBV), cannabidivarin (CBDV), cannabichromevarin (CBCV), cannabigerovarin (CBGV), cannabinodiol (CBDL), cannabielsoin (CBE), cannabitriol (CBT), $\Delta$ 9-tetrahydrocannabinol ( $\Delta$ 9-THC), $\Delta$ 9-tetrahydrocannabivarin $(\Delta 9$-THCV), and $\Delta 8$-tetrahydrocannabinol ( $\triangle 8$-THC). All chemical structures and properties were obtained from PubChem Compound, National Center for Biotechnology Information, U.S. National Library of Medicine. Molinspiration was used for the calculation of molecular properties and bioactivity score. The parameters were molecular weight (MW), number of hydrogen acceptor (HBA), number of hydrogen donor (HBD), partition coefficient (cLogP), polar surface area (PSA) and number of rotatable bonds (NROTB). We predicted bioactivity scores for G Protein-Coupled Receptors (GPCR) ligand, ion channel modulator, kinase inhibitor, nuclear receptor ligand, protease inhibitor and enzyme inhibitor. Lipinski's rule was used as reference to determine the drug-like properties of the phytocannabinoids. All compounds have $\mathrm{MW}<500, \mathrm{HBA}<10, \mathrm{HBD}<5$, TPSA $<140 \AA^{2}$ and NRTOB $<10$. Bioactivity score showed an active or moderately active in all compounds. Fifteen compounds were detected to have one violation. CBT did not violate any of the Lipinski's Ro5 and demonstrated as a good drug-like property and for oral absorption. This suggests that CBT can be further tested for potential orally active drugs.
\end{abstract}

Keywords phytocannabinoids, in silico, drug-like properties, Cannabis sativa

\section{INTRODUCTION}

Cannabis sativa is an annual flowering plant from Cannabaceae family. It is also known in many names, such as cannabis, marijuana, ganja and hemp. This plant has been used for industrial, medicinal and recreational. Generally, marijuana has high amount of $\Delta$ 9-tetrahydrocannabinol ( $\Delta 9$-THC) and low amount of cannabidiol (CBD). Hemp or industrial hemp, contains high amount of CBD and very low in $\triangle 9-\mathrm{THC}$. C. sativa contains chemical compounds that can be classified into 11 types: cannabidiol (CBD), cannabinol $(\mathrm{CBN})$, cannabinodiol $(\mathrm{CBDN})$, cannabichromene (CBC), cannabigerol (CBG), cannabicyclol (CBL), cannabielsoin (CBE), cannabitriol (CBT), $\Delta$ 9-tetrahydrocannabinol $(\Delta 9$-THC), and $\Delta 8$ tetrahydrocannabinol $(\triangle 8$-THC) and miscellaneous types [1]. Pharmacological investigations on phytocannabinoids has been reviewed, mainly on CBD and THC [2, 3, 4]. Various compounds in cannabis were described as anti-cancer [5], anti-nausea [2], anti-arthritic [2], anti-inflammatory [6, 8], anti-microbial [7] and anti-oxidant [8]. The pharmacological properties show beyond recreational uses; however, cannabis is not yet approved by the US Food, Drugs and Administration for medical use. 
Natural products (NPs) inspire new drug development. Our nature provides an enormous source of new molecules. In 2015, more than 540 compounds were described [9] which provides information on the bioactive metabolites to scientists. Concern are raised in understanding the mechanism that regulate the secondary metabolites in cannabis, identifying novel biosynthetic pathways to produce specialized metabolites and to discover new drugs to meet the world health challenges [3]. An ideal drug should have good pharmacological effects and bioavailability profile [10]. A good bioavailability profile includes permeability, solubility, lipophilicity, stability and solubility. In a drug-likeness prediction, pharmacokinetics (absorption, distribution, metabolism and excretion (ADME)), toxicology, potency and selectivity of an identified compound has to be optimized. Optimization is a crucial step for drug development. Therefore, in silico approaches is to predict ADME.

Rule of five (Ro5) was developed to predict oral bioavailability (absorption via intestinal) [10]. Ro5 states that $\mathrm{HBD}<5, \mathrm{HBA}<10, \mathrm{MW}<500 \mathrm{Da}, \operatorname{cog} \mathrm{P}<5$ and no more than one number of violation. Another important aspect for compounds targeted to the central nervous system is penetration to blood-brain barrier (BBB), which PSA and lipophilicity of compound were used o design an equation [11].

There is situation where compounds violate Ro5, such as tetracycline and rifampicin. They can still permeate a phospholipid bilayer significantly [12]. There are drugs that behave beyond Ro5. Properties that should be optimized for lipid bilayer permeation, such as H-bond donors and acceptors neutralization, and formation of zwitterion. Transporter proteins may also be targeted by a prodrug approach or structural adaptations. This is because genetic polymorphism has the influence on non-linear type of kinetics, interactions between drugs and variability [12].

The linkages between molecular physicochemical properties and drug discovery are useful to accelerate drug discovery and development. NPs contain many new rings system that will provide source of structure for drug design and discovery. The NPs with good biological properties will have more attraction in the development of drug discovery. In general, an application of molecular physicochemical properties rules or filter is a simple tool for orally active compounds aimed for drug development. To the best of our knowledge, there has been no study yet, on the drug-like properties of phytocannabinoids of Cannabis sativa.

\section{MATERIALS AND METHODS}

\section{Data for in silico assessment}

We analyzed sixteen compounds of phytocannabinoid using PubChem Compound: CBD, CBDA, CBN, CBC, CBG, CBL, CBV, CBDV, CBCV, CBGV, CBDL, CBE, CBT, $\triangle 9$-THC, $\Delta 9-\mathrm{THCV}$, and $\Delta 8-\mathrm{THC}$. All molecular structures were obtained in the form of Simplified Molecular-Input Line-Entry System (SMILES). The line notations for describing each of the molecular structure were imported using PubChem Compound. We used The American Standard Code for Information Interchange (ASCII) strings form in all software. The SMILES are listed as Table 1. Molecular structure is obtained from ChemIDplus software.

Table 1 The SMILES

\begin{tabular}{ll}
\hline \multicolumn{1}{c}{ Compound } & Canonical SMILES \\
\hline CBD & CCCCCC1 $=\mathrm{CC}(=\mathrm{C}(\mathrm{C}(=\mathrm{C} 1) \mathrm{O}) \mathrm{C} 2 \mathrm{C}=\mathrm{C}(\mathrm{CCC} 2 \mathrm{C}(=\mathrm{C}) \mathrm{C}) \mathrm{C}) \mathrm{O}$ \\
\hline $\mathrm{CBDA}$ & $\mathrm{CCCCCC} 1=\mathrm{CC}(=\mathrm{C}(\mathrm{C}(=\mathrm{C} 1 \mathrm{C}(=\mathrm{O}) \mathrm{O}) \mathrm{O}) \mathrm{C} 2 \mathrm{C}=\mathrm{C}(\mathrm{CCC} 2 \mathrm{C}(=\mathrm{C}) \mathrm{C}) \mathrm{C}) \mathrm{O}$ \\
\hline $\mathrm{CBN}$ & $\mathrm{CCCCCC} 1=\mathrm{CC} 2=\mathrm{C}(\mathrm{C}(=\mathrm{C} 1) \mathrm{O}) \mathrm{C} 3=\mathrm{C}(\mathrm{C}=\mathrm{CC}(=\mathrm{C} 3) \mathrm{C}) \mathrm{C}(\mathrm{O} 2)(\mathrm{C}) \mathrm{C}$ \\
\hline $\mathrm{CBC}$ & $\mathrm{CCCCCC} 1=\mathrm{CC} 2=\mathrm{C}(\mathrm{C}=\mathrm{CC}(\mathrm{O} 2)(\mathrm{C}) \mathrm{CCC}=\mathrm{C}(\mathrm{C}) \mathrm{C}) \mathrm{C}(=\mathrm{C} 1) \mathrm{O}$ \\
\hline
\end{tabular}




\begin{tabular}{ll}
\hline CBG & CCCCCC1 $=\mathrm{CC}(=\mathrm{C}(\mathrm{C}(=\mathrm{C} 1) \mathrm{O}) \mathrm{CC}=\mathrm{C}(\mathrm{C}) \mathrm{CCC}=\mathrm{C}(\mathrm{C}) \mathrm{C}) \mathrm{O}$ \\
\hline CBL & $\mathrm{CCCCCC} 1=\mathrm{CC} 2=\mathrm{C}(\mathrm{C} 3 \mathrm{C} 4 \mathrm{C}(\mathrm{C} 3(\mathrm{C}) \mathrm{C}) \mathrm{CCC} 4(\mathrm{O} 2) \mathrm{C}) \mathrm{C}=\mathrm{C} 1) \mathrm{O}$ \\
\hline CBV & $\mathrm{CCCC} 1=\mathrm{CC} 2=\mathrm{C}(\mathrm{C}=\mathrm{C} 1) \mathrm{O}) \mathrm{C} 3=\mathrm{C}(\mathrm{C}=\mathrm{CC}(=\mathrm{C} 3) \mathrm{C}) \mathrm{C}(\mathrm{O} 2)(\mathrm{C}) \mathrm{C}$ \\
\hline CBDV & $\mathrm{CCCC} 1=\mathrm{CC}(=\mathrm{C}(\mathrm{C}(=\mathrm{C} 1) \mathrm{O}) \mathrm{C} 2 \mathrm{C}=\mathrm{C}(\mathrm{CCC} 2 \mathrm{C}(=\mathrm{C}) \mathrm{C}) \mathrm{C}) \mathrm{O}$ \\
\hline CBGV & $\mathrm{CCCC} 1=\mathrm{CC}(=\mathrm{C}(\mathrm{C}(=\mathrm{C} 1) \mathrm{O}) \mathrm{CC}=\mathrm{C}(\mathrm{C}) \mathrm{CCC}=\mathrm{C}(\mathrm{C}) \mathrm{C}) \mathrm{O}$ \\
\hline CBDL & $\mathrm{CCCCCC} 1=\mathrm{CC}(=\mathrm{C}(\mathrm{C}(=\mathrm{C} 1) \mathrm{O}) \mathrm{C} 2=\mathrm{C}(\mathrm{C}=\mathrm{CC}(=\mathrm{C} 2) \mathrm{C}) \mathrm{C}(=\mathrm{C}) \mathrm{C}) \mathrm{O}$ \\
\hline CBE & $\mathrm{CCCCCC} 1=\mathrm{CC} 2=\mathrm{C}(\mathrm{C} 3 \mathrm{C}(\mathrm{CCC}(\mathrm{C} 3 \mathrm{O} 2)(\mathrm{C}) \mathrm{O}) \mathrm{C}(=\mathrm{C}) \mathrm{C}) \mathrm{C}(=\mathrm{C} 1) \mathrm{O}$ \\
\hline CBT & $\mathrm{CCCCCC} 1=\mathrm{CC} 2=\mathrm{C}(\mathrm{C}(=\mathrm{C} 1) \mathrm{O}) \mathrm{C} 3=\mathrm{C}(\mathrm{CCC}(\mathrm{C} 3 \mathrm{O})(\mathrm{C}) \mathrm{O}) \mathrm{C}(\mathrm{O} 2)(\mathrm{C}) \mathrm{C}$ \\
\hline$\Delta 9-\mathrm{THC}$ & $\mathrm{CCCCCC} 1=\mathrm{CC} 2=\mathrm{C}(\mathrm{C} 3 \mathrm{C}=\mathrm{C}(\mathrm{CCC} 3 \mathrm{C}(\mathrm{O} 2)(\mathrm{C}) \mathrm{C}) \mathrm{C}) \mathrm{C}(=\mathrm{C} 1) \mathrm{O}$ \\
\hline$\Delta 9-\mathrm{THCV}$ & $\mathrm{CCCC} 1=\mathrm{CC} 2=\mathrm{C}(\mathrm{C} 3 \mathrm{C}=\mathrm{C}(\mathrm{CCC} 3 \mathrm{C}(\mathrm{O} 2)(\mathrm{C}) \mathrm{C}) \mathrm{C}) \mathrm{C}(=\mathrm{C} 1) \mathrm{O}$ \\
\hline$\Delta 8-\mathrm{THC}$ & $\mathrm{CCCCCC} 1=\mathrm{CC} 2=\mathrm{C}(\mathrm{C} 3 \mathrm{CC}(=\mathrm{CCC} 3 \mathrm{C}(\mathrm{O} 2)(\mathrm{C}) \mathrm{C}) \mathrm{C}) \mathrm{C}(=\mathrm{C} 1) \mathrm{O}$ \\
\hline
\end{tabular}

\section{Determination rules}

Lipinski's rules were used to assess the drug-like properties [10]. Molinspiration software provided data on molecular weight, number of hydrogen bond donor (HBD), number of hydrogen bond acceptor (HBA), polar surface area (PSA) and number of rotatable bond (NROTB). Lipinski suggested the Ro5 properties that would make it likely orally an active drug in human [10]. The rules for molecular descriptors are, partition coefficient $\log \mathrm{P}(\mathrm{cLog} \mathrm{P})<5$, molecular weight $(\mathrm{MW})<500$, number of hydrogen bond acceptors $(\mathrm{HBA})<10$, number of hydrogen bond donors $(\mathrm{HBD})<5$, and no more than one number of violation. A drug is expected to be absorbed over $90 \%$ if the PSA value is less than $60 \AA 2$ [13]. The molecular polar surface area (PSA) is calculated based on $\mathrm{O}$ - and $\mathrm{N}$ - centered polar fragments. The value of number of rotatable bonds (NROTB) should be less than 10 for an assessment to the absorptive ability [14].

We used Molinspiration to predict the drug likeness score for GPCR ligands, ion channel modulators, kinase inhibitors, nuclear receptor ligands, and protease inhibitors. The activity scores were compared against $\sim 100,000$ average drug-like molecules. The score discriminates between active and inactive molecules. Bioactivity score indicates the activeness of a compound. Score $>0$ is considered active, score $-5.0-0.0$ indicates moderately active, and score<-5.0 shows inactive compound. We used Molsoft to evaluate drug likeness model score. Drug likeness model score is to determine its similarity to the known drugs. The balance of various molecular properties and structure features are the two main features used as reference. Molsoft predicts an overall drug-likeness score using 5000 of marketed drugs from WDI (as positives) and 10,000 of carefully selected non-drug compounds (as negatives). Score that falls within the drug range is considered drug likeness.

\section{RESULTS AND DISCUSSION}

We evaluated drug likeness of phytocannabinoids according to Lipinski's Ro5. The bioactivity score is used as an indicator to the activeness of compounds.

\section{Drug likeness of phytocannabinoids}

Drug likeness filters that supported by physicochemical properties is useful to expedite the process of drug discovery and development [15]. Table 2 shows the drug-likeness of the sixteen phytocannabinoids. All compounds possess molecular weight less than $500 \mathrm{Da}$, HBA less than 10, HBD less than 5, TPSA less than 140 and violation of less than 2 . All compounds violated the cLogP except for CBT. These results predicted that all sixteen compounds possess good oral absorption. Compounds with TPSA of less than 60 are 
predicted to be $100 \%$ absorbed. Only CBDA and CBT are predicted to have absorptivity of more than $90 \%$. However, Ro5 is dedicated for compounds that are not active transporters substrates [16]. Nevertheless, scientists believe that majority of drugs are substrates for some transporter [17]. The principles in Biopharmaceutics Drug Disposition Classification System (BDDCS) are equally applicable to drugs within Ro5 and compounds that sit beyond Ro5 [18]. BDDCS developed upon Ro5 and may be considered to predict characteristics for both complying and non-compliance to Ro5. Nonetheless, all 16 phytocannabinoids possess good oral bioavailability.

Table 2 Properties of phytocannabinoids in Cannabis sativa

\begin{tabular}{|c|c|c|c|c|c|c|c|}
\hline Compound & $\begin{array}{c}\text { MW } \\
(\leq \mathbf{5 0 0}) *\end{array}$ & $\begin{array}{l}\text { HBA } \\
(\leq 10) *\end{array}$ & $\begin{array}{l}\text { HBD } \\
(\leq 5)^{*}\end{array}$ & $\begin{array}{l}\operatorname{cLogP} \\
(\leq 5)^{*}\end{array}$ & Violation & $\begin{array}{c}\text { TPSA, } \mathbf{A}^{2} \\
\left(\leq 140 * ; \leq 60^{\#}\right)\end{array}$ & $\begin{array}{c}\text { NRTOB } \\
(\leq 10)^{*}\end{array}$ \\
\hline CBD & 314.47 & 2 & 2 & 7.14 & 1 & 40.46 & 6 \\
\hline CBDA & 358.48 & 4 & 3 & 6.43 & 1 & 77.75 & 7 \\
\hline $\mathrm{CBN}$ & 310.44 & 2 & 1 & 6.81 & 1 & 29.46 & 4 \\
\hline $\mathrm{CBC}$ & 314.47 & 2 & 1 & 7.50 & 1 & 29.46 & 7 \\
\hline $\mathrm{CBG}$ & 316.49 & 2 & 2 & 7.84 & 1 & 40.46 & 9 \\
\hline$\Delta 9-\mathrm{THC}$ & 314.47 & 2 & 1 & 6.69 & 1 & 29.46 & 4 \\
\hline$\triangle 9-\mathrm{THCV}$ & 286.42 & 2 & 1 & 5.62 & 1 & 29.46 & 2 \\
\hline$\Delta 8-\mathrm{THC}$ & 314.47 & 2 & 1 & 7.64 & 1 & 29.46 & 4 \\
\hline CBL & 314.47 & 2 & 1 & 6.64 & 1 & 29.46 & 4 \\
\hline $\mathrm{CBV}$ & 282.38 & 2 & 1 & 5.75 & 1 & 29.46 & 2 \\
\hline CBDV & 286.42 & 2 & 2 & 6.08 & 1 & 40.46 & 4 \\
\hline $\mathrm{CBCV}$ & 286.42 & 2 & 1 & 6.44 & 1 & 29.46 & 5 \\
\hline CBGV & 288.43 & 2 & 2 & 6.78 & 1 & 40.46 & 7 \\
\hline CBDL & 310.44 & 2 & 2 & 6.63 & 1 & 40.46 & 6 \\
\hline $\mathrm{CBE}$ & 330.47 & 3 & 2 & 5.79 & 1 & 49.69 & 5 \\
\hline CBT & 346.47 & 4 & 3 & 4.61 & 0 & 69.92 & 4 \\
\hline
\end{tabular}

Good oral absorption*, Completely absorbed ${ }^{\#}$

\section{Bioactivity}

A good drug should possess good absorptive property and bioactivity score. Table 3 represents bioactivity scores of the sixteen phytocannabinoids. The score indicates active $>0,-5.0-0.0$ indicates moderately active compound, and score <-5.0 shows an inactive compound. All sixteen phytocannabinoids are a mixture of active and moderately active compounds. CBDA shows moderately active in all bioactive scores. All compounds were predicted active as GPCR ligand, nuclear receptor ligand and enzyme inhibitor, except for CBDA, which was at moderate level. All compounds were predicted moderately active as kinase inhibitor.

Table 3 Bioactivity scores of active compounds in Cannabis sativa

\begin{tabular}{lcccccc}
\hline Compound & $\begin{array}{l}\text { GPCR } \\
\text { ligand }\end{array}$ & $\begin{array}{l}\text { Ion } \\
\text { channel } \\
\text { modulator }\end{array}$ & $\begin{array}{l}\text { Kinase } \\
\text { inhibitor }\end{array}$ & $\begin{array}{l}\text { Nuclear } \\
\text { receptor } \\
\text { ligand }\end{array}$ & $\begin{array}{l}\text { Protease } \\
\text { inhibitor }\end{array}$ & $\begin{array}{l}\text { Enzyme } \\
\text { inhibitor }\end{array}$ \\
\hline CBD & 0.35 & $-0.14^{*}$ & $-0.48^{*}$ & 0.38 & $-0.19^{*}$ & 0.33 \\
CBDA & $-0.39 *$ & $-0.05^{*}$ & $-0.74^{*}$ & $-0.30^{*}$ & $-0.63^{*}$ & $-0.09 *$ \\
CBN & 0.50 & 0.02 & $-0.08^{*}$ & 0.60 & 0.11 & 0.22 \\
CBC & 0.22 & 0.08 & $-0.13^{*}$ & 0.68 & 0.23 & 0.49
\end{tabular}




\begin{tabular}{lcccccc} 
CBG & 0.31 & 0.16 & $-0.11^{*}$ & 0.67 & 0.09 & 0.53 \\
$\Delta 9-$ THC & 0.64 & $-0.03^{*}$ & $-0.34^{*}$ & 0.50 & $-0.05^{*}$ & 0.43 \\
$\Delta 9-$ THCV & 0.62 & $-0.04^{*}$ & $-0.41^{*}$ & 0.52 & $-0.16^{*}$ & 0.43 \\
$\Delta 8-$ THC & 0.64 & $-0.01^{*}$ & $-0.39^{*}$ & 0.56 & $-0.01^{*}$ & 0.46 \\
CBL & 0.31 & 0.19 & $-0.21^{*}$ & 0.61 & 0.15 & 0.32 \\
CBV & 0.46 & 0.01 & $-0.13^{*}$ & 0.63 & 0.02 & 0.20 \\
CBDV & 0.31 & $-0.16^{*}$ & $-0.56^{*}$ & 0.39 & $-0.31^{*}$ & 0.32 \\
CBCV & 0.16 & 0.07 & $-0.18^{*}$ & 0.72 & 0.15 & 0.50 \\
CBGV & 0.26 & 0.17 & $-0.15^{*}$ & 0.71 & 0.0 & 0.54 \\
CBDL & 0.32 & 0.03 & $-0.17^{*}$ & 0.60 & 0.13 & 0.08 \\
CBE & 0.29 & 0.03 & $-0.43^{*}$ & 0.47 & 0.02 & 0.31 \\
CBT & 0.44 & 0.16 & $-0.16^{*}$ & 0.55 & 0.18 & 0.28 \\
\hline
\end{tabular}

moderately active compounds*

\section{Drug likeness model}

Drug likeness is an indicator to predict overall score based on known drugs. CBDA, $\triangle 9-\mathrm{THCV}, \mathrm{CBL}, \mathrm{CBE}$ and CBT possess active drug likeness score $(0.20,0.07,0.20,0.39,0.57)$ while the rest are in moderate. There is an exceptional for other compounds that did not show a good drug likeness score. The second metabolites in NPs are synthesized by organism, according to evolutionary selection. However, this is an exception to the Ro5 [19]. Cannabis sativa has been cross bred actively and producing many strains and hybrids, which influenced phytocannabinoids [20]. The biophysics of formation of the ligand binding sites controls the physicochemical properties of drugs. Phytocannabinoids have been widely tested for therapeutic purposes [21, 22]. However, drug likeness model predicted mixture of active and moderately active. MW, HBD and HBA influence how ligand binding sites are formed in proteins, but lipophilicity does not directly relate to the biophysics of binding site information [19]. Therefore, all compounds may be further investigated using various machine learning techniques [23].

CBT does not violate the Ro5 and has $100 \%$ oral absorptivity based on the in silico prediction. Bioactive scores are active for all tests but moderate as kinase inhibitor. Molsoft predicted CBT as a high potential of drug-likeness. CBT was discovered in 1966 [24] and an x-ray analysis identified the stereochemistry of the molecule [25]. CBT compound is summarized in a chemistry database, but lack of pharmacology information [26]. In oral absorption, drug crosses the luminal membrane by the path of passive diffusion or active transport. Passive diffusion consists of paracellular and transcellular (lipophilic) pathways. In a paracellular pathway, drug will diffuse through aqueous pores, located at the tight junctions which are between the intestinal enterocytes. Whilst, in transcellular pathway drug will diffuse across the lipid cell membrane of the enterocytes. On the other hand, transporters mediate the active transport pathway. The physicochemical properties and its potential affinity for various transport proteins will determine each route [27].

\section{CONCLUSION}

The Ro5 filter is useful in predicting compound with good oral absorption by comparing with drugs that have reached users. CBT is the only phytocannabinoid that does not violate any of the Ro5. Therefore, CBT maybe further examine for a candidate drug. All sixteen phytocannabinoids show good oral absorption with a $100 \%$ absorptivity, except for CBDA and CBT (>90\%). All phytocannabinoids obeyed Lipinski's rules which indicate good bioavailability. In addition, bioactive scores are determined as, active or moderately active. All phytocannabinoids possess active score for GCPR ligand and enzyme inhibition except CBDA 
is predicted as moderately active. Based on the prediction, we conclude that all phytocannabinoids are potential for further oral drug development.

\section{ACKNOWLEDGEMENTS}

We thank the Universiti Pendidikan Sultan Idris, Malaysia for the sabbatical program funding, University of Northern Colorado, USA for providing the Marijuana Research lab facilities and Forest Research Institute Malaysia for in silico consultation.

\section{REFERENCES}

[1] ElSohly, M.A., Radwan, M.M., Gul W., Chandra S. and Galal, A. (2017). Phytochemistry of Cannabis sativa L. in Phytocannabinoids: Unravelling the complex chemistry and pharmacology of Cannabis sativa. Springer International Publishing Switzerland, 1-36.

[2] Burstein, S. (2015). Cannabidiol (CBD) and its analogs: a review of their effects on inflammation. Bioorgan. Med. Chem. 23, 1377-1385.

[3] Andre, C.M., Hausman, J. and Guerriero, G. (2016). Cannabis sativa: The plant of the thousand and one molecules. Frontier in Plant Science. 7(19).

[4] Giacoppo, S., Mandolino, G., Galuppo, M., Bramanti, P. and Mazzon, E. (2014). Cannabinoids: new promising agents in the treatment of neurological diseases. Molecules. 19, 18781-18816.

[5] Javid F.A., Phillips, R.M., Afshinjavid, S., Verde, R and Ligresti, A. (2016). Cannabinoid pharmacology in cancer research: A new hope for cancer patients? European Journal of Pharmacology, 775, 1-14

[6] DeLong, G. T., Wolf, C. E., Poklis, A., and Lichtman, A. H. (2010). Pharmacological evaluation of the natural constituent of Cannabis sativa, Cannabichromene and its modulation by tetrahydrocannabinol. Drug Alcohol Depend. 112,126-133.

[7] Isahq M.S., Afridi, M.S., Ali, J., Hussain, M.M., Ahmad, S. and Kanwal, S. (2015). Proximate composition, phytochemical screening, GC-MS studies of biologically active cannabinoids and antimicrobial activities of Cannabis indica. Asian Pacific Journal of Tropical Disease. 5 (11), 897-902.

[8] Rajan,T.S., Giacoppo,S.,Iori, R., De Nicola, G.S., Grassi, G., Pollastro, F., Bramanti, P. and Mazzon, E. (2016). Anti-inflammatory and antioxidant effects of a combination of cannabidiol and moringin in LPS-stimulated macrophages. Fitoterapia. 112,104-115.

[9] Gould, J. (2015). The Cannabis crop. Nature. 525, S2-S3.

[10] Lipinski, C.A. (1997). Experimental and computational approaches to estimate solubility and permeability in drug discovery and development settings. Adv. Drug Deliv. Rev. 23, 3-25.

[11] Abraham, M.H., Chada, H.S., Mitchell, R.C.(1994). Hydrogen bonding. 33 factors that influence the distribution of solutes between blood and brain. J. Pharm. Sci. 83,1257-1268.

[12] Krämer, S.D., Aschmann, H.E., Hatibovic,M., Hermann, K.F., Neuhaus, C.S., Brunner, C., Belli, S. (2016). When barriers ignore the "rule-of-five". Adv. Drug Deliv. Rev. 62-74.

[13] Prasanna, S., Doerrksen, R.J. (2009). Topological polar surface area: A useful descriptor in 2D-QSAR. Curr Med Chem. 16:21-41.

[14] Yu, C., Zhang X.D., Guan, H.Y., Gr, C.H., Wu, Y., Han, G.X. (2007). Prediction of solvation for energy of small organic moleculars based on support vector regression algorithm. Chemistrymag 9:54.

[15] Macarron, R., Leungo, J.I., (2011). Yin and Yang in medicinal chemistry: what does drug-likeness mean? Future Med.Chem. 3:505-507.

[16] Lipinski, C.A., Lombardo, F., Dominy, B.W., Feeney, P.J. (2001). Experimental and computational approaches to estimate solubility and permeability in drug discovery and development settings. Adv Drug Rev. 46:3-26

[17] Benet, L.Z., Hosey, C.M., Ursu, O., Oprea, T.I. (2016). BDDCS, the Rule of 5 and drugability. Adv Drug Rev.101:89-98.

[18] Wu, C.Y., Benet, L.Z. (2005). Predicting drug disposition via application of BCS: transport/absorption/elimination interplay and development of a biopharmaceutics drug disposition classification system. Pharm. Res. 22:11-23. 
[19] Lipinski, A. C. (2016). Rule of five in 2015 and beyond: Target ad ligand structural limitations, ligand chemistry structure and drug discovery project decisions. Adv Drug Rev. 101: 34-41

[20] Desa, S., Schwabe, A.,.McGlaughlin, M, Brown, C.E., Hyslop, R.M. (2017). Analysis of chemotypes in retail Cannabis strains. 253rd American Chemical Society National Meeting \& Exposition, San Francisco, CA. 2-6 April, 2017.

[21] Hyslop, R.M., Saviola, A., Bydalek, S., Brown, C.E., Desa, S., Thomas, M., Magiotta, A, Mackessy, S., Hansen, C., Brown, M. (2017). In vitro anti-neoplastic activity of specific phytocannabinoids of Cannabis sativa. 253rd American Chemical Society National Meeting \& Exposition, San Francisco, CA. 2-6 April, 2017.

[22] Hyslop, R.M., Brown, C.E., Magiotta A., Morgan, B., Brown, M., Sherman, T., Petty, D., Desa, S., O’Neil, J., Flora, S., Kellogg, K., Hansen, C., Bydalek, S., Cale, T., Laster, C., Folsom, J., Hawkinson, A. (2017). Development of a cannabinoid-based Cell-in-a Box ${ }^{\circledR}$ therapeutic system targeted toward malignant tumors. 253rd American Chemical Society National Meeting \& Exposition, San Francisco, CA. 2-6 April, 2017.

[23] Tian, S., Wang, J., Li, Y., Li, D., Xu, L., Hou, T. (2015). The application of in silico drug-likeness predictions in pharmaceutical research. Adv Drug Delivery Reviews. 86: 2-10

[24] Obata, Y., Ishikawa, Y. (1966). Studies on the Constituents of Hemp Plant (Cannabis sativa L.) Agricultural and Biological Chemistry. 30(6), 619-620

[25] McPhail, A.T., ElSohly, H.N., Turner, C.E., ElSohly, M.A. (1984). Stereochemical assignments for the two enantiomeric pairs of 9,10-dihydroxy- $\triangle 6$ a (10a) tetrahydrocannabinols $x$-ray crystal structure analysis of ( \pm$)$ trans-cannabitriol. J. Nat. Prod. 47(1):138-142

[26] National Center for Biotechnology Information. PubChem Compound Database; CID=11551959, https://pubchem.ncbi.nlm.nih.gov/compound/11551959 (accessed Oct. 1, 2017).

[27] El- Kattan, A., Varma, M. (2012). Oral Absorption, Intestinal Metabolism and Human Oral Bioavailability, Topics on Drug Metabolism, Dr. James Paxton (Ed.), InTech, DOI: 10.5772/31087. Available from: https://www.intechopen.com/books/topics-on-drug-metabolism/oral-absorption-intestinal-metabolism-andhuman-oral-bioavailability- 